\title{
CHRONIC ENTEROCOLITIS COMBINED WITH STREPTOZOTOCIN- INDUCED DIABETES IN RATS: MECHANISM OF OXIDATIVE STRESS DEVELOPMENT
}

\author{
${ }^{1}$ N. V. Lisnianska, ${ }^{2}$ M. I. Marushchak, ${ }^{2}$ I. V. Antonyshyn, ${ }^{30}$ O. P. Mialiuk \\ ${ }^{1}$ CHERNIVTSI MEDICAL COLLEGE OF BUKOVINIAN STATE MEDICAL UNIVERSITY, CHERNIVTSI, UKRAINE; \\ 2I. HORBACHEVSKY TERNOPIL STATE MEDICAL UNIVERSITY, TERNOPIL, UKRAINE; \\ ${ }^{3}$ RIVNE STATE BASIC MEDICAL COLLEGE, RIVNE, UKRAINE
}

Background. Despite numerous studies on chronic inflammatory processes in colon, the complex problem of chronic enterocolitis (CEC) remains relevant.

Objective. The aim of the research is to evaluate the lipid peroxide oxidation and antioxidant defence system in rats suffering from chronic enterocolitis development with underlying streptozocine-induced diabetes mellitus.

Methods. The study involved 106 white non-linear male rats. Diabetes mellitus (DM) was modeled by a single intraperitoneal administration of streptozotocin to animals (Sigma Aldrich, USA, at a dose of $60 \mathrm{mg} / \mathrm{kg}$ of body weight). CEC was induced by a free access of animals to $1.0 \%$ solution of carrageenan in drinking water for 1 month.

Results. In the wall of small intestine of DM rats, lipid peroxide oxidation increases and the activity of enzyme link of antioxidant defence decreases reliably. The course of experimental CEC in rats is accompanied by the increase in free radical oxidation in the wall of small intestine and simultaneous increase of enzyme activity of antioxidant defence system, compared to the control.

In cases of CEC with underlying DM in rats, the development of oxidative stress in the wall of small intestine is caused by the statistically significant increase in levels of diene conjugates and thiobarbituric acid reactive substances, $(p<0.01)$ and the decrease in activity of SOD and catalase.

Conclusions. The activation of free radical reactions is an important non-specific mechanism of inflammation development in tissues of small and large intestine in cases of diabetes mellitus.

KEY WORDS: chronic enterocolitis; diabetes mellitus; lipid peroxidation; antioxidant defence system; experiment.

\section{Introduction}

A difficult social and economic situation, deterioration of living conditions, aggressiveness of the environment and other negative stress factors contribute to an increase in incidence of digestive diseases in the population. Digestive diseases are one of the most common among chronic diseases in developed countries. According to a number of studies, their share is $8-10 \%$ [1-5]. Chronic enterocolitis (CEC) is one of the diseases, which are based on the combination of elements of inflammation and dystrophy of mucous membrane with functional disorders in small and large intestines. This disease takes account of about $10 \%$ of the

Corresponding author: Maria Marushchak, Department of Functional Diagnostics and Clinical Pathophysiology, I. Horbachevsky Ternopil State Medical University, 1 Maidan Voli, Ternopil, Ukraine, 46001

Phone number: +380979901202

E-mail: marushchak@tdmu.edu.ua total chronic pathology of digestive system organs, and its prevalence is $5-12$ cases per 1000 people [6]. Despite numerous studies on chronic inflammatory processes in colon, the complex problem of chronic enterocolitis remains relevant $[7,8]$. For a long time this term defined a variety of pathological conditions of intestine, which was due to the lack of sufficiently clear notions about the nature of the disease. From the standpoint of modern concepts, chronic enterocolitis should be considered as a clinical and morphological phenomenon characterized by pain and dyspeptic syndromes typical for intestinal diseases with morphologically determined signs of epithelium dystrophy, the decrease in crypts depth and development of various severity lymphoplasmatic infiltration [9]. According to the official data, the incidence of CEC in the world is 50-230 cases per 100,000 people [10]. About 
$15-20 \%$ of the world's population suffer from CEC. In the United States, over 20 million adults have symptoms of this disease. [11]. The annual increase in number of enterocolitis patients in the world is 5-20 cases per 100,000 people. Epidemiological calculations in the US proved that in white population, CEC is found in 3-5 times more often than in African Americans, while Jews are threatened in 3.5 times more than non-Jewish people. The disease occurs in all age groups, but the highest incidence is in 20-40-year-old individuals [12]. In the overall structure of gastroenterological pathology in America, CEC ranks first and accounts for $28 \%$ of all cases of treatment by gastroenterologists. About $12 \%$ of the patients seek medical advice from a general practitioner with complaints specific to CEC. CEC is diagnosed the most commonly in young people: $13.5 \%$ of people are aged $15-34,13 \%$ of them are $35-44$ years old and $9 \%$ are aged 45 and older. Therefore, the disease causes great economic harm to the society both the cost of medical care and by indirect factors, which include a compensation for temporary disability. [13]. However, it should be noted that in modern literature there is controversial information on CEC as an independent nosological form, and the presence of functional intestinal disease - an irritable bowel syndrome, is mentioned more often, while the changes in the intestinal mucosa are interpreted by the authors as morphofunctional ones, which causes the complexity of clinical and laboratory diagnostics and different understanding of CEC $[14,15]$.

From the pathogenetic point of view, the diseases related to the class of free radical pathology are widespread, starting with birth (bronchopulmonary dysplasia, retinopathy in preterm infants, enterocolitis, etc.). [16, 17]. The weakening of antioxidant defence and uncontrolled enhancement of lipid peroxidation processes is one of the important links in the pathogenesis of autonomic dysfunction, atopic dermatitis, dental pathology, diabetes mellitus, as well as pathology of gastrointestinal tract, enterocolitis as well $[18,19]$. In this case peroxide lipid oxidation products, including malonic dialdehyde, which destabilize cellular membranes, reach high concentrations in blood and tissues $[20,21]$. To date, a large amount of data has been accumulated proving the participation of free radical processes in the pathogenesis of CEC [16].

Therefore, the aim of our study was to evaluate the lipid peroxide oxidation and anti- oxidant defence system in rats suffering from chronic enterocolitis development with underlying streptozocine-induced diabetes mellitus.

\section{Methods}

The study involved 106 white non-linear male rats, which were kept on a standard vivarium diet of I. Horbachevsky Ternopil State Medical University. During the experiment the principles of the European Convention for the Protection of Animals used for Experimental and Other Scientific Purposes were followed. The experimental rats were divided into four groups: the $1^{\text {st }}$ - control (intact animals), the $2^{\text {nd }}-$ animals with diabetes mellitus, the $3^{\text {rd }}-$ animals with chronic enterocolitis, the $4^{\text {th }}$ - animals with diabetes mellitus and chronic enterocolitis. Diabetes mellitus (DM) was modeled by a single intraperitoneal administration of streptozotocin to the animals aged 2 months, (Sigma Aldrich, USA, at a dose of $60 \mathrm{mg} / \mathrm{kg}$ of body weight) [22]. Right before its injection, streptozotocin was dissolved in 0.1 molar citrate buffer (pH 4.5); the control group received the appropriate amount of citrate buffer. The study involved the animals with the glucose rate at least $10.8 \mathrm{mmol} / \mathrm{L} 2$ weeks after streptozotocin administration. Chronic enterocolitis was induced by a free access of animals to $1.0 \%$ solution of carrageenan in drinking water for 1 month [23, 24]. Euthanasia of animals was performed by heart puncture under anaesthesia, in accordance with the requirements of the Animal Care Committee [25].

The state of lipid peroxide oxidation (LPO) was evaluated by the concentration of diene conjugates (DC) and thiobarbituric acid reactive substances (TBARS). The content of DC was determined by direct spectrophotometry, the principle of which is to isolate native fatty acids by extraction with a mixture of equal volumes of heptane and isopropanol, followed by measuring the optical density of heptane phase of lipid extract. Absorption at a wavelength of $232 \mathrm{~nm}$ evidences the content of DC [26]. To determine TBARS, we used the method of M. Mihara (1980), which consists in the formation of a coloured complex by the interaction of lipid peroxide oxidation products with thiobarbituric acid, by means of a standard set. The activity of antioxidant enzymes: catalase, was recorded simultaneously with the LPO processes [27], superoxide dismutase [28].

The obtained data were subjected to statistical processing $[29,30]$. To verify the conformity of the data samples with the normal dis- 
tribution law, the calculation by Shapiro-Wilk test was applied. Due to the lack of data matching to the normal distribution at the significance rate $\mathrm{p}<0.05$, the median characteristics were estimated: median (Me), first and third quartiles (Q25-Q75). The level of statistical significance of sample differences was evaluated using nonparametric Mann-Whitney $U$ test. Differences were considered statistically significant at the achieved rate of $p<0.05$.

\section{Results}

The increase of free radical oxidation processes in small intestine wall in the presence of the studied pathologies has been established $(p<0.05)$. For instance, in cases of streptozotocininduced diabetes, the content of DC increased statistically significantly by $66.93 \%$ and of TBARS by $71.22 \%$, compared to the control values (Table 1). As the lipid peroxide oxidation increased, the activity of enzyme system of antioxidant defence system decreased, in particular, the activity of SOD decreased by $38.02 \%$ and that of catalase by $58.82 \%$.

Experimental CEC was accompanied by the increase of lipid peroxide oxidation in the wall of small intestine (DC by $35.16 \%$ and TBARS by $27.65 \%, p<0.01$ ) with simultaneous increase of enzyme activity of antioxidant defence system (SOD by $29.90 \%$ and catalase by $21.65 \%$, $\mathrm{p}<0.01$ ) compared to the control (Table 1).

The statistically significant activation of free radical oxidation processes in the rats with $C E C$ combined with DM (the level of DC increased by $104.84 \%$ and of TBARS by $115.02 \%$ respectively, $p<0.01$ ) was evidenced. A significant decrease in activity of SOD by $131.09 \%$ and of catalase by $21.65 \%(p<0.001)$, compared to the control, was found.

\section{Discussion}

Thus, in cases of experimental diabetes, the prooxidant-antioxidant disbalance in the wall of small intestine was characterized by the development of oxidative stress. According to the literature, the increase in blood glucose levels with its auto-oxidation is one of the causes of intensification of free radical oxidation [31].

In current studies there are no reliable data on the effect of systematic consumption of carrageenan on the body of an adult, child, foetus and when this supplement comprises the diet of pregnant women. Studying this problem in the clinic is very problematic, so there is an urgent need of studying the influence of carrageenan on metabolic parameters in an experimental model.

The obtained data of experimental CEC prove that under the conditions of normal digestion due to acid hydrolysis, carrageenan splits into low and high molecular particles, which trigger free radical processes. Previous studies evidence the involvement of macrophages in the absorption of carrageenan with the formation of heterolysosomes, which leads to the implementation of harmful effects of lysosomal enzymes. On the other hand, macrophages are established to be the source of free radicals [32]. In order to ensure antioxidant equilibrium, an antioxidant defence system is activated simultaneously against the action of the external factor, proving the mobilization of protective and adaptive mechanisms associated with the excessive

Table 1. Rates of free radical oxidation in the wall of small intestine of the rats with chronic enterocolitis combined with streptozotocin-induced diabetes, Me (Q25-Q75)

\begin{tabular}{|c|c|c|c|c|}
\hline Rate & Control & $\begin{array}{c}\text { DM } \\
\text { (group 2) }\end{array}$ & $\begin{array}{c}\text { CEC } \\
\text { (group 3) }\end{array}$ & $\begin{array}{l}\mathrm{DM}+\mathrm{CEC} \\
\text { (group 4) }\end{array}$ \\
\hline DC, st.un./g of tissue & $\begin{array}{c}2.89 \\
(2.50 ; 3.25)\end{array}$ & $\begin{array}{c}4.83^{*} \\
(4.25 ; 5.29)\end{array}$ & $\begin{array}{c}3.91 * \\
(3.71 ; 4.09)\end{array}$ & $\begin{array}{c}5.92 * \\
(5.76 ; 6.15) \\
p_{1,2}<0.01\end{array}$ \\
\hline TBARS, $\mathrm{mmol} / \mathrm{mg}$ & $\begin{array}{c}3.33 \\
(2.78 ; 3.80)\end{array}$ & $\begin{array}{c}5.71 * \\
(5.53 ; 5.95)\end{array}$ & $\begin{array}{c}4.26 * \\
(4.00 ; 4.57)\end{array}$ & $\begin{array}{c}7.16^{*} \\
(6.98 ; 7.31)^{\star} \\
\mathrm{p}_{1,2}<0.01\end{array}$ \\
\hline $\begin{array}{l}\text { SOD activity, st. un/mg of } \\
\text { proteins }\end{array}$ & $\begin{array}{c}17.17 \\
(16.28 ; 18.18)\end{array}$ & $\begin{array}{c}10.64^{*} \\
(8.95 ; 12.02)\end{array}$ & $\begin{array}{c}22.30 * \\
(21.43 ; 23.35)\end{array}$ & $\begin{array}{c}7.43^{*} \\
(6.38 ; 8.08) \\
\mathrm{p}_{1,2}<0.001\end{array}$ \\
\hline $\begin{array}{c}\text { Catalase activity, } \\
\mathrm{mmol} \cdot \mathrm{min} / \mathrm{mg} \text { of proteins }\end{array}$ & $\begin{array}{c}41.64 \\
(40.78 ; 42.55)\end{array}$ & $\begin{array}{c}17.15^{\star} \\
(16.16 ; 17.65)\end{array}$ & $\begin{array}{c}50.66^{*} \\
(51.88 ; 54.55)\end{array}$ & $\begin{array}{c}11.46 * \\
(10.85 ; 12.07) \\
\mathrm{p}_{1,2}<0.001\end{array}$ \\
\hline
\end{tabular}

Notes: * - the difference between the control and experimental groups is statistically significant $(p<0.05-0.001) ; p_{1}-$ the reliability value between the groups 2 and $4 ; p_{2}$-the reliability value between the groups 3 and 4 . 
production of superoxide anion radical. Darren $\mathrm{N}$. Seril et al. note that oxidative stress and free radical damage to mucous membranes of small and large intestines are one of the signs of peptic ulcer and, probably, one of the factors of carcinogenesis under these conditions [33].

The inflow of toxin (carrageenan) into the systemic circulation largely depends on the state of cytoplasmic membranes of organs and tissues that perform barrier functions, where the intestine is very important $[34,35]$. One of the main pathogenetic factors regulating the permeability of membranes is the activation of free radical oxidation processes, which are crucial mechanism that provides the availability of lipid-protein complexes of membrane for phospholipase and proteases respectively [36]. This fact justifies the results obtained by us regarding the statistically significant activation of free radical oxidation processes in the rats with CEC combined with DM.

Reducing SOD activity may be due to the damaging effects of free radicals on the metalloprotein complex of enzyme containing copper, zinc or manganese. Low activity of catalase may be associated with the increase in concentration of hydrogen ions, which leads to the development of a proton form of an enzyme having an altered catalytic activity. It should be noted that in the experimental group 4 the rates of LPO were the highest and those of the antioxidant

\section{References}

1. Dmitriieva TV. Analysis of the patterns of the formation of morbidity and disability and the scientific justification of modern approaches to medical and social expertise in diseases of the digestive organs: the author's abstract of the diss. of doctor of med. sciences. Moscow: Littera; 2011. p. 42.

2. Ivashkin VT, Lapina TL, Maiev IV, Trukhmanov AS. Rational pharmacotherapy of diseases of the digestive system. A guide for practicing doctors. Moscow: Littera; 2011. p. 848.

3. Ivashkin VT, Komarov FI. State and prospects of development of gastroenterology. Therapeutic Archive. 2002;2:5-8.

4. Loginov AS, Parfionov AI. Irritable bowel syndrome: ten-year experience of studying in the CSRIG. Russian Gastroenterological Journal. 2000;3:17-21.

5. Loginov AS, Parfionov AI. Diseases of the intestine. Guide for doctors. M.: Medicine; 2000. p. 572-87. system were the lowest, compared to the other experimental groups. Therefore, the activation of free radical reactions is an important nonspecific mechanism of inflammation development in tissues of small and large intestine in cases of diabetes mellitus.

\section{Conclusions}

In the wall of small intestine of streptozotocin-induced diabetic rats, lipid peroxide oxidation increases (DC content is higher than in the control by $66.93 \%$ and TBARS by $71.22 \%$, respectively $p<0.001$ ) and the activity of enzyme link of antioxidant defence decreases reliably (SOD by $38.02 \%$ and catalase by $58.82 \%$ ).

The course of experimental chronic enterocolitis in rats is accompanied by the increase in free radical oxidation in the wall of small intestine (DC by $35.16 \%$ and TBARS by $27.65 \%$, $p<0.01$ ) with simultaneous increase of enzyme activity of antioxidant defence system (SOD by $29.90 \%$ and catalase by $21.65 \%, \mathrm{p}<0.01)$, compared to the control.

In cases of chronic enterocolitis with underlying diabetes mellitus in rats, the development of oxidative stress in the wall of small intestine is associated with the statistically significant increase in levels of DC (by 104.84\%) and TBARS (by $115.02 \%$ ), $p<0.01$ and the decrease in activity of SOD (by $131.09 \%$ ) and catalase (by $21.65 \%$ ).

6. Bielousova OYu. Chronic nonspecific non-ulcerative colitis in children. Gastroenterology. Pediatrician Practice. 2013;42-52.

7. Bielousov YuV, Sadchikov VD, Belousova OYu. Chronic colitis and irritable bowel syndrome in children: diagnosis and differential diagnosis. Medical Practice. 2000;3:59-62.

8. Grinievich VB, Simanenkov VI, Uspenskii YuP. Irritable bowel syndrome: clinic, diagnosis, treatment. St. Petersburg: 2000. p. 57.

9. Tsimbolova EG, Potapov AS, Shcherbakov PL, Kaganov BS. Clinical course and outcomes of inflammatory bowel diseases in children. Proceedings of the 7th Congress of Pediatricians of Russia Pediatric Gastroenterology: present and future. Moscow; 2002. p. 321-22.

10. Masievich, TsG, Sitkin SI. Modern pharmacotherapy of chronic inflammatory bowel diseases. Aqua Vitae. 2001;1:37-41. 
11. Ardatskaya MD. Irritable Bowel Syndrome. Gastroenterology. Polyclinic. 2010;5:60-65.

12. Targan SR, Shanahan F, Karp LC. Inflammatory Bowel Disease: From Bench to Bedside. 2nd ed. Kluwer Academic Publishers; 2003. p. 904.

13. Ardatskaya MD. Irritable Bowel Syndrome. Gastroenterology. Polyclinic. 2010;5:60-65.

14. Frolkis AV. Diseases of the intestines. SPb: OOO Publishing House Foliant; 2003. p. 192.

15. Harewood GC, Sharma VK. Impact of colonoscopy preparation quality on detection of suspected colonic neoplasia. Gastrointestinal Endoscopy. 2003;58(1):76-9.

16. Korovina NA, Zakharova IN, Obynochnaya EG. Use of antioxidants in pediatric practice. Moscow: Lita. http: media consilium / 03_09 / Feb-2004. Accessed Feb 92014.

17. Vasilieva EM, Bakanov MI, Poddubnaya $A E_{,}$ Shor TA. Peroxide oxidation of lipids in neurological pathology in children. Clinical Laboratory Diagnostics. 2005;2:8-12.

18. Oliinyk YaV. Disorders in lipid peroxidation and their correction in children suffering from atopic dermatitis. Herald of Scientific Researches. 2007;3:39-42.

19. Novozhilova GP, Aksionova VM, Mozgovaya LA. State of lipid peroxidation and antioxidant system in plasma, erythrocytes and saliva of children with oral cavity pathology aggravated with intestinal dysbiosis. Moscow: Litera; 2016. http: www.stomatburg.ru/articles/klin. Accessed Nov 52016.

20. Sukhanova GA, Serebrov VYu. Cell biochemistry. Tomsk: Charodei; 2000. p. 91-142.

21. Kurashvili VA, Mailam L. New possibilities of oxidative stress prevention. Journal of Natural Medicine. 2001;1:7-14.

22. Ordodi VL, Paunescu V, Ionac M, et al. Indomethacin inhibits thymic involution in mice with streptozotocininduced diabetes. Artificial Organs. 2008;32(1):66-70.

23. Moyana TN, Lalonde JM. Carrageenan-induced intestinal injury in the rat-a model for inflammatory bowel disease. Ann Clin Lab Sci. 1990;20(6): 420-426.
24. Gubina-Vakulyk GI, Kolousova NG, Ivanenko TO, Gorbach TV, Korobchanskyj VO, inventors; Kharkiv National Medical University, assignee. Method of simulating chronic gastroenterocolitis. Ukraine. Patent a201014510. 2012. Jan 1.

25. Reznikov O. General ethical principles of experiments on animals. Endocrinology. 2003;8(1): 142-145.

26. Volchegorskii IA. Nalimov AG, Yarovinskii BG, Lifshits RI. Comparison of different approaches to the determination of lipid peroxidation products in heptane-isopropanol extracts of blood. Issues of Medical Chemistry. 1989;1:127-130.

27. Koroliuk MA, Ivanova LI, Maiorova IG. Method for determination of catalase activity. Lab. Business. 1988;1:16-18.

28. Makarenko EV. Complex determination of the activity of superoxide dismutase and glutathione reductase in erythrocytes in patients with chronic liver diseases. Lab. Business. 1988;11:48-50.

29. Glants S. Medico-biological statistics. Moscow: Praktika; 1999. p. 459.

30. Rebrova OYu. Statistical analysis of medical data. Using the STATISTICA application package. Moscow: MediaSfera. 2002. p. 312.

31. Zaichik ASh, Churilov LP. Fundamentals of pathochemistry. St. Petersburg: Elby; 2001. p. 255.

32. Terence Moyana J-M, Lalonde A. Carrageenaninduced Intestinal Injury: Possible Role of Oxygen Free Radicals. Annals of Clinical and Laboratory Science. 2010;21(4):258-63.

33. Darren N, Jie S, Guang-Yu L, Yang Chung S. Oxidative stress and ulcerative colitis-associated carcinogenesis: studies in humans and animal models. Carcinogenesis. 2003;24(3):353-62.

34. Saveliev VS, Pietukhov VA. Peritonitis and endotoxin aggression. Moscow; 2012. p. 326.

35. Yakovliev MYu. Elements of endotoxin theory of physiology and human pathology. Human Physiology. 2003;29(4):98-109.

36. Riazantseva NV, Novytskyi VV. Typical disturbances in the molecular organization of erythrocyte membrane in somatic and mental pathology. Successes of Physical Sciences. 2004;35(1):53-65.

Received: 2017-08-29 